\title{
Gastrointestinal Nematode Parasites of Small Ruminants and Anthelmintics Efficacy Test in Sheep of Haramaya District, Eastern Ethiopia
}

\author{
Jemal Ahmed ${ }^{1}$, Ararsa Duguma ${ }^{1, ~}$, Dareje Regassa ${ }^{1}$, Dinaol Belina ${ }^{1}$, Roba Jilo ${ }^{2}$ \\ ${ }^{1}$ Haramaya University, College of Veterinary Medicine, Diredawa, Ethiopia \\ ${ }^{2}$ Oromia Regional State Pastoral Area Development Commission, Finfinne, Ethiopia
}

Email address:

Jemal3373@gmail.com(J. Ahmed),ararsad@yahoo.com (A. Duguma),dereregassa@gmail.com (D. Regassa), belina.timketa@gmail.com (D. Belina),roberto.jilo@yahoo.com (R. Jilo)

*Corresponding author:

\section{To cite this article:}

Jemal Ahmed, Ararsa Duguma, Dareje Regassa, Dinaol Belina, Roba Jilo. Gastrointestinal Nematode Parasites of Small Ruminants and Anthelmintics Efficacy Test in Sheep of Haramaya District, Eastern Ethiopia. Animal and Veterinary Sciences. Vol. 5, No. 3, 2017, pp. 39-44. doi: $10.11648 /$ j.avs.20170503.11

Received: August 1, 2017; Accepted: August 13, 2017; Published: June 19, 2017

\begin{abstract}
The combination of cross-section and controlled field trail were carried out from December 2015 to June 2016 at Haramaya District, Eastern Hararhge, Ethiopia to evaluate the prevalence ofgastrointestinal nematodes and anthelmintic efficacy test in naturally infected small ruminants using faecal egg count reduction (FECR) test. From a total of 372 faecal samples examined using fecal flotation technique about 57\% (212/372) samples were positive to gastrointestinal nematodes. Coprological investigation revealed that sheep and goats in district were infested with varieties of nematode parasites. The strongyles species were highly prevalent nematode parasites identified at about $22.3 \%$ (83/372) followed by trichuris $9.1 \%$ (34/372) and strongyloides 5.6\% (21/372); whereas mixed infections of strongyles and strongyloides were recovered at lowest rate which accounted for about $5.1 \%(19 / 372)$. From considered risk factors age and kebele showed significant association $(\mathrm{p}<0.05)$ with prevalence of nematodes parasites. The study revealed that $53.29 \%(97 / 182)$ of goats and $60.53 \%(115 / 190)$ sheep were found positive, while 58\% (115/198) in female and 55.74\% (97/174) in male and showed no significant difference $(p>0.05)$ between these factors. Mc Master egg counting in sheep harbored nematode parasites showed relatively similar percentage with no significant difference; but more of examined animals were classified in the range of moderate to heavy infections. The faecal egg count reduction test against albendazole, Tetraclozash and ivermectin indicated that $97.59 \%, 98.79 \%$ and $99.56 \%$ respectively which indicated an overall of very good state of efficacy against gastrointestinal nematodes of sheep. Therefore this study revealed that small ruminants of the study area harbored considerable level of gastrointestinal nematodes parasites which need further studies on species identification, larval ecology and strategic deworming with proper practice of available anthelmintics in small ruminants of the study area.
\end{abstract}

Keywords: Anthelmintic Efficacy, Gastrointestinal Nematodes, Small Ruminants, Haramaya, Ethiopia

\section{Introduction}

Sheep and goats are mainly found in arid and semi- arid areas of sub-Saharan Africa. They play a vital role in rural economies through the provision of meat, milk, household income, manure and skin. Compared to cattle and camels, sheep and goats contribute a larger proportion of readily available meat in the diets of pastoralists. They have been estimated to provide up to $30 \%$ of the meat and $15 \%$ of the milk supplies in sub-Saharan Africa where thrive in a wide range of ecological regions often in conditions too harsh for the beneficial rearing of cattle. Small ruminants have also been reported to survive better under drought conditions than cattle due to their low body mass and low metabolic requirements which in turn minimize their water requirements and maintenance needed in arid and semi-arid 
areas. The frequent droughts and large tsetse infected areas in sub-Saharan Africa requires more small ruminants in order to supplement cattle production [1].

In spite of huge population and importance of small ruminants, Ethiopia has benefited little from this enormous resource owning to a multitude of problems like poor nutrition, poor animal production systems, reproductive inefficiency, management constraints, lack of veterinary care, and disease being the most important [2].

Gastrointestinal parasite infections are a world-wide problem for both small- and large-scale farmers, but their impact is greater in sub-Saharan Africa in general and Ethiopia in particular due to the availability of a wide range of agro-ecological factors suitable for diversified hosts and parasite species [3]. Several Studies indicated that gastrointestinal parasites are most problems of small ruminants. These cause losses due to morbidity, production losses and mortalities [4]. Helminthes parasites are one of the biggest causes of production losses where nematode parasites considered to be the most prevalent and important disease that affecting small ruminant in world. They are responsible for both direct and indirect losses [5].

Effective management of gastrointestinal (GI) parasites in grazing livestock mostly depends on the strategic use of efficacious chemotherapy [6]. However, the indiscriminate use of anthelmintics causes widespread development of anthelmintic resistance in different GI nematodes population [7]. Anthelmintic resistance is the condition in which normal dosage of drug not able to produce a consistent reduction in number of worms or excreted eggs [8]. The narrow range of available drug development and slow rate a new emerging drug contribute for anthelmintic resistance threat to global which requires carefully monitoring and management. Anthelmintic resistance in small ruminants' production is considering as a main constraints throughout the world. This result is serious problem due to non-availability of new drugs [9].

In Ethiopia use of anthelmintics has been practiced for many years with available drugs which represent a major veterinary service cost [10]. A Few reports are observed on the resistance of gastrointestinal nematodes to anthelmintic drugs in case of Ethiopia. These includes low efficacy of tetramisole in goats in southern Oromia [11]; albendazole, ivermectin and tetramisole resistance in goats in eastern Ethiopia where nematodes parasite show resistance [12].

According to the report of Zeryehun [13] there was high prevalence of helminthes parasites with $59.89 \%$ of nematodes and moderate to severe infection of sheep and goat in the present study. This implies nematode parasites were one of the major problems that could hamper health and productivity of sheep and goats and need further study and evaluation of anthelmintic efficacy in the study area. Therefore the objectives of this study were to determine the status of nematode parasites and evaluate efficacy of commonly used anthelmintic drugs in small ruminants of Haramaya district, eastern Ethiopia.

\section{Materials and Methods}

\subsection{Study Area}

The study was conducted from November, 2015 to June, 2016 in and around Haramaya district. Haramaya district is located in eastern Hararghe zone, Oromia regional state, Ethiopia. The district is located approximately at $508 \mathrm{~km}$ east of capital city Addis Ababa.

The elevation of the area is about $2000 \mathrm{~m}$ above sea level and geographically located at $41^{\circ}, 59^{\prime} 58^{\prime \prime}$ and $09^{\circ}, 10^{\prime}, 24^{\prime \prime}$ latitude and longitude, respectively. The annual rainfall is believed approximately an average of $900 \mathrm{~mm}$. There are about four season (from mid -March to mid- may) with short rainy season, short dry season (from end May to end of June), a long wet season (from July to mid-October) and along dry season (from end of October to February). The mixed crop-livestock farming system is practiced in area; where pasture production is expected after short rain season and continuing until the end of long wet season. Livestock population and farming system mainly mixed type agriculture in the area. Livestock population of the district estimated 193,334; of these populations 64,510 represent cattle, 28,359 goats, 18,930 sheep, 15,277 donkeys, 5 mules, 530 camels and 65,723 poultry (Haramaya Disrict Agricultural Development Bureau, 2010).

\subsection{Study Population and Sampling Method}

The study populations were small ruminants which were selected randomly from four peasant associations (PAs) of Haramaya district. The study animals were local breeds and kept under traditional extensive management system. The selected PAs were: Damota, Tuji-Gabsa, Tinike and Bate in which equal proportions of samples were collected from each site. The criteria for inclusion in the controlled field trial concerned with the history of anthelmintic usage, owner's willingness and parasite burdens (EPG) for anthelmintic efficacy test. In this study the risk factors such as animal's age, sex and site were included.

\subsection{Study Design}

The study was cross-sectional study that design for estimation of status nematodes and a controlled field trial for anthelminthic efficacy test. All animals were selected for evaluation of the status of nematode parasites and anthelmintic efficacy test. Nematode egg positive animals divided into four groups which consists three treated and one control groups. The treated groups were received anthelminthic drugs, whereas the control group untreated. Then each group randomly allocated into one of the three anthelmintic groups and one untreated control group. The group consist 60 animals in which each group had 15 animals.

McMaster egg counting method was used to determine the number of egg per gram (EPG) in the positive fecal samples. The degree of infestations were determined by counting the eggs per gram faeces through MC Master Technique according to Hansen and Perry [14] and classified as(50-800 EPG- Light infection level; 800-1200 EPG-Moderate 
infection level and >1200 EPG- Heavy infection level).

The efficacies of three selected drugs namely Albendazole, Ivermectin and Tetraclozan against nematode parasites in each group were examined. These drugs were selected based on pre-assessment of commonly used anthelmintics presented by private pharmacy and government veterinary clinic in the study district. Efficacy of anthelmintics was calculated using arithmetic mean of FECRT of the treated and untreated animals as described by Coles et al. [15]. The result of mean FEC on $14^{\text {th }}$ day post treatment and control group of sheep were used for analysis.

The anthelmintic used were those imported by companies that are licensed to distribute veterinary drugs in the country and shown in (Table 1).

Table 1. Drugs used for anthelminthic efficacy test against sheep nematodes.

\begin{tabular}{|c|c|c|c|}
\hline Trade name & Generic name & Manufacture & Dose \\
\hline Albenda-QK 300MG & Albendazole & Chengdu QiankunVet. Pharm. co. Ltd., China & $7.5 \mathrm{mg}$ per $\mathrm{kg}$ \\
\hline Ivermectin $1 \%$ & Ivermectin & Chengdu QiankunVet. Pharm. co. Ltd., China & $0.2 \mathrm{mg}$ per $\mathrm{kg}$ \\
\hline Tetraclozash-900 & Tetramisole + Oxyclozanide & Ashish Life Science PVT, India & $7.5 \mathrm{mg}$ per $\mathrm{kg}$ \\
\hline
\end{tabular}

\subsection{Sample Size Determination}

The sample size was determined to evaluate the status of parasites by the formula described by Thrusfield [16]. Accordingly, a 95\% confidence level and 5\% precision value were used and the total sample size were calculated to be 369 using expected prevalence $59.89 \%$ of previous study by Zeryehun [13] in the study area. All animals were selected to determine status of nematode parasites and positive animals were used for anthelmintics efficacy test by classifying into four groups based on fecal egg count (FEC) that were conducted before treatment. Sheep with FEC greater than 200 in each group was randomly allocated into one of the three anthelmintic treated groups and one untreated control group.

\subsection{Sample Collection and Fecal Examination}

Fecal samples were collected directly from the rectum of small ruminants in which the samples were put into faecal universal bottle, labeled and kept in ice-bag container and transported to Haramaya University parasitology laboratory. The examination for presence of eggs were done by using a simple test tube flotation technique as described by Hansen and Perry [14]. The identification of egg species parasites were done according to the procedure described by Soulsby [17].

\subsection{Data Analysis}

Data analysis was done by using SPSS version 16 software program type. Descriptive statistics was used to determine the prevalence of the parasites. Association between categorical factors such as Age, sex, species and origin of animals and parasitism were compared using Chi-square tests for independence. In all analyses, confidence level was held at $95 \%$ and $\mathrm{P}<0.05$ were set for significance value. The anthelmintic efficacy test was evaluated by calculating FECRT\% by applying the formula $\mathrm{E}=[1-(\mathrm{T} / \mathrm{C})]^{*} 100$, where $\mathrm{E}$ = percentage efficacy; $\mathrm{C}=$ mean number of eggs in the control group; $\mathrm{T}=$ mean number of eggs in the treated group; where the value of FECRT \% less than $95 \%$ was suspected as developed resistance or poor efficacy [15].

\section{Results}

From total samples examined the overall prevalence of nematode parasites showed 57\% (212/372). A prevalence of $53.29 \%(97 / 182)$ was indicated in goats and $60.53 \%$ $(115 / 190)$ in sheep. Statistical analysis showed that there was significant variation among selected sites of animals $(\mathrm{p}<$ $0.05)$. Relatively high prevalence of nematodes were found in animals of age less than 1 year and there was no statistically significant variation between age of the study animals $(\mathrm{P}=$ 0.091) (Table 2).

Table 2. Prevalence of gastrointestinal nematodes with different risk factors.

\begin{tabular}{lllll}
\hline Risk factors & $\begin{array}{l}\text { No. of } \\
\text { examined }\end{array}$ & $\begin{array}{l}\text { No. of } \\
\text { positive }\end{array}$ & $\begin{array}{l}\text { Prevalence } \\
\text { (\%) }\end{array}$ & $\chi^{2}$ (P-value) \\
\hline Age & & & & \\
$<$ 1years & 148 & 91 & 61.49 & \\
1 to 2 years & 142 & 84 & 59.15 & $6.465(0.091)$ \\
$>3$ years & 82 & 38 & 46.34 & \\
Species & & & & \\
Sheep & 190 & 115 & 60.53 & $1.982(0.159)$ \\
Goats & 182 & 97 & 53.29 & \\
Sex & & & & \\
Female & 198 & 115 & 58 & \\
Male & 182 & 97 & 55.74 & \\
PA & & & & \\
Bate & 93 & 41 & 44.086 & \\
Damota & 93 & 46 & 49.46 & \\
Tuji-Gabisa & 93 & 64 & 68.82 & \\
Tinike & 93 & 61 & 65.59 & \\
\hline
\end{tabular}

The most predominant GIT nematode species identified in sheep and goats in study area were strongyle, trichuris and strongyloides with prevalence of $22.3 \%, 9.1 \%$ and $5.6 \%$, respectively (Table 3 ).

Table 3. Prevalence of gastrointestinal nematode parasites species in study area.

\begin{tabular}{llll}
\hline Nematodes egg type & $\begin{array}{l}\text { No. of } \\
\text { examined }\end{array}$ & $\begin{array}{l}\text { No. of } \\
\text { positive }\end{array}$ & $\begin{array}{l}\text { Prevalence } \\
\text { (\%) }\end{array}$ \\
\hline Strongyle & 372 & 83 & 22.3 \\
Strongyloides & 372 & 21 & 5.6 \\
Trichuris & 372 & 34 & 9.1 \\
Strongyle +Trichuris & 372 & 32 & 8.6 \\
Strongyle +Strongyloides & 372 & 19 & 5.1 \\
Strongyle +Strongyloides & 372 & 23 & 6.2 \\
+Trichuris & 372 & 212 & 57 \\
Total & & &
\end{tabular}


Table 4. Degree of nematodes infection in sheep based on FEC in the study area.

\begin{tabular}{llll}
\hline Degree of infection & No. Infected & Percentage (\%) & $\chi^{\mathbf{2}}$ (p-value) \\
\hline Light & 13 & 21.7 & \\
Moderate & 18 & 30.0 & $1.43(0.489)$ \\
Heavy & 29 & 48.3 & \\
Total & 60 & 100 & \\
\hline
\end{tabular}

Mc Master egg counting in sheep harbored nematode parasites showed relatively similar percentage with no significant difference; but more of examined animals were classified in the range of moderate to heavy infections as shown in Table (4).

Percentage in reduction of fecal egg count for efficacy evaluation of albendazole, ivermectin and Tetraclozash indicated that three drugs were found as $97.59 \%, 98.79 \%$ and $99.56 \%$. The percentage of FECR in treated group of sheep for each anthelmintic drug was indicated in Table (5).

Table 5. Mean fecal egg counts before and after treatment of sheep and percentage reduction.

\begin{tabular}{lllll}
\hline Drug & No. Animals used in each group & Pre-treatment mean \pm SE & Post-treatment mean \pm SE & Efficacy (\%) \\
\hline Ivermectin & $(\mathrm{n}=15)$ & $880 \pm 114.3$ & $7.3333 \pm 6.65$ & 99.56 \\
Albendazole & $(\mathrm{n}=15)$ & $833.3 \pm 96.94$ & $40 \pm 19$ & 97.59 \\
Tetraclozash & $(\mathrm{n}=15)$ & $826.67 \pm 85.33$ & $20 \pm 10.69$ & 98.79 \\
Control & $(\mathrm{n}=15)$ & $700 \pm 136.97$ & $1660 \pm 141.35$ & \\
\hline
\end{tabular}

\section{Discussion}

A cross-sectional study conducted to evaluate status of nematode parasites in small ruminant of the present study indicated that overall prevalence of 57\% (212/372) in sheep and goats. The result indicated $60.53 \%(115 / 190)$ infection rate in sheep which agree with finding of [18] $55.1 \%$ in South West of Ethiopia; Mohammed et al. [19] 64.6\% in Gursum district, Eastern Oromia Ethiopia and Zeryehun [13] $65.1 \%$ in Haramaya district, Eastern Ethiopia. However, this finding is lower than previous result obtained in study of GIT nematodes of small ruminants by Getachew et al., [20] and Kumsa et al. [21] that reported $72 \%$ in Bedelle district south Oromia and $86 \%$ in Bishoftu district central Oromia respectively. This study showed that the prevalence of nematode parasites in goats was 53.29\% (97/182) which agree with finding of Zeryehun [13] in and around Haramaya district Eastern Ethiopia and Tigist et al. [18] in South West Ethiopia who reported $54.61 \%$ and $52.6 \%$ respectively while it contrary to the previous study done by Kumsa et al. [21] in central Ethiopia that reported $83.1 \%$ prevalence of nematodes of goats. The difference of findings could be occurred due to difference in sample size taken and type of utilized technique, ecological and climate diversity as well as the existing host range [22].

In this finding prevalence of GIT nematodes infection was higher in age group of animals less than 1year whereas infection lower in age group greater than 3 years and showed statically no significant difference $(p>0.05)$. This was contrast to report of Diriba and Birhanu [23], South Eastern Ethiopia; Tigist et al. [18] in South West Ethiopia. According to Soulsby [24] when small ruminants are infected with nematode parasites, primary solid immunity is developed against GIT nematodes for next infection and this acquired immunity that help in expelling the parasites before it establish itself in the hosts whereas new born and younger animal lack strong immunity as relative to adult animals.

Prevalence in male was 55.74\% (97/174) and that of female was $58 \%(115 / 198)$ with greater infections in female than male. However, sex of animals did not show significant association with the prevalence of nematodes infection ( $P>0.05)$. The absence of association between sex of animals and the prevalence of nematodes infection is agree with previous study of Bekele et al. [25] and Muluneh et al. [26] in Southern and in North west of Ethiopia respectively. This indicated that male and female have equal chance of infection if they are exposed to the same contaminated communal grazing pasture. The possible reason for slightly higher prevalence in females are due to female animals are more susceptible to parasitic infection during pregnancy and per-parturient period due to the stress which causes reduction of immune status [27].

The study revealed that when species was analyzed as risk factor the prevalence of nematodes in sheep and goats had no significant variation $(\mathrm{P}>0.05)$ which was similar with finding of Tigist et al. [18] and also they were infected with the same principal parasitic species this might be due to similarities in agro ecology in management of both sheep and goats, kept by tradition extensive management system [22]. The samples were also collected from animals in mixed flocks and the same grazing pattern.

From selected PAs of the district in the current study, the highest prevalence of nematodes parasites infection was observed in Tuji-Gabisa 68.82\% (64/93) and the lowest was in Bate $44.086 \%$ (41/93), whereas the association between selected sites with prevalence of nematode parasites showed significant difference $(\mathrm{P}<0.05)$. This variation in prevalence might be due to the various in management practice and owners awareness to deworm their animals among selected PAs of the study area. The area of Tuji-Gabisa is wet as compared to the rest area.

Mc Master egg counting in sheep harbored nematode parasites showed relatively similar percentage with no significant difference; but more of examined animals were classified in the range of moderate to heavy infections. About $48.3 \%$ of infected animals were with heavy infections whereas $30 \%$ moderate and $21.7 \%$ with light infection. The reason for higher percentage of moderate to 
heavy infections might be associated with less development of immunity and poor management of flocks from factors associated with occurrence of nematode parasites.

Anthelmintic efficacy test on sheep against nematode parasite indicated percentage efficacy of $97.59 \%$ albendazole, $98.79 \%$ Tetraclozash and $99.56 \%$ ivermectin. A field controlled efficacy test was based on reduction in worm number and indicated that three drugs are effective in removing the parasites. The present study is similar with the previous studies in Ethiopia done on efficacy of albendazole and Tetraclozash imported in Ethiopia which showed that effectiveness of both drugs as reported by Niguse et al. [28] and Achene et al. [29]. The Ivermectin was highly effective in reducing fecal egg count in this study. This agrees with finding of $[30,20,28]$. The reason why anthelmintics are still effective in the study area may be due to the farmers are deworming only severely infected animals from the flock that could minimize the risk of resistance development. The finding of this study is disagree with that of Wassene and Kumsa [31] which indicated that presence of resistance in nematodes of goat farm in Hawassa, Sourthern Ethiopia. This study suggest that use of those drugs at their dosage level and formulation prescribed by manufacturers, have tendency in controlling nematode parasites in study area.

\section{Conclusion}

Coprological examination for analyzing of gastrointestinal nematode eggs in small ruminants of present study showed that the animals harbored high prevalence of nematode parasites. Among considered risk factors, study sites had significance difference with prevalence of nematode parasites. The controlled field trial study revealed that there was visible reduction of EPG account in treated sheep post treatment relatively with untreated group. In this study absence of resistance development against ivermectin, Tetraclozash and albendazole indicating use of these drugs at their dosage level and formulation prescribed by manufacturers, have tendency in controlling nematode parasites. From the above conclusions strategic deworming of small ruminants using these drugs could be practiced to minimize the burden of gastrointestinal nematodes infection in the study area and regular study should be carried out on the status of gastrointestinal nematodes and resistance of anthelmintic drugs considering different scenario and integration of more sensitive method with varieties of anthelmintic brand were set as recommendations.

\section{Acknowledgements}

The authors would like to acknowledge Haramaya University, College of Veterinary Medicine for financial and material support. We would like to thank farmers of the study area who allowed and assisted us in collection of relevant information and fecal samples from their animals to carry out this research.

\section{References}

[1] Wesongah, L. J. O., Chemulitti, F. D., Wesonga, L., Munga, P., Ngare and Murilla, G. A.(2003). Trypanosomosis and other parasitic diseases affecting sheep and goats production in two group ranches, Narok district, Kenya.

[2] Sissay, M. (2007). Helminth Parasites of Sheep and Goats in Eastern Ethiopia. Epidemiology and Anthelmintic Resistance and its Management. Faculty of Veterinary Medicine and Animal Science. Department of Biomedical Sciences and Veterinary Public Health Division of Parasitology and Virology Uppsala Sweden Doctoral thesis Swedish University of Agricultural Sciences.

[3] Fikru, R., Teshale, S., Reta, D. and Yosef, K. (2006). Epidemiology of Gastrointestinal parasites of Ruminants in Western Oromia, Ethiopia Intern J Appl Res Vet Med. 4(1).

[4] Shimelis, D., Asmare, A. and Wudu, T. (2011). Epidemiology of gastrointestinal helminthiasis of small ruminants in selected sites of North Gonder Zone North West Ethiopia. Ethio. Vet. J15: 57-68.

[5] Hoste, H., Torres-aciste, J. F. I. and Agullarcaballera, A. J. (2008). Parasite interaction in goats: Is immunoregulation involved in the control of gastrointestinal nematodes? Parasite Immunol30: 79-88.

[6] Good, B., Hanrahan, J. P., Waal, D. J., Pattern, J. and Kinsella, A. (2012). Anthelmintic resistance nematodes in Irish commercial Sheep Flocks. The state of play. Ir Vet 565: 21.

[7] Kaplan, R. M. (2004). Drug resistance in nematodes of veterinary importance a state report. TrendsParasitol 20: 477481 .

[8] Silvestre, A., Leignel, V., Berrage, B., Gasnier, N. and Humbert, J. F. (2002). Sheep and goats nematode resistance to anthelmintics: Pro and Cans among breeding management factorVet Res 33: 465-480.

[9] Papodopoulasa, E. (2008). Anthelmintic resistance in sheep nematode Small. Rum. Res 76: 99-103.

[10] Biffa, D., Jobbery, Y. and Chakn, H. (2006). Ovine helminthosis, a major health constraint to productivity of sheep in Ethiopia. Anim. Health. Res Rev 7: 107-118.

[11] Kumsa, B. and Wossene, A. (2006). Efficacy of albendazole and tetramisoleanthelmintics against Haemonchuscontortus in experimentally infected lambs. Intern. Appl. Res. Vet. Med 4: 94-99.

[12] Sissay, M. M., Asefa, A., Uggla, A. and Waller, P. J. (2006). Anthelmintic resistance of nematode parasites of small ruminants in eastern Ethiopia: Exploitation of refugia to restore anthelmintic efficacy. Vet. Parasitol: 135-346.

[13] Zeryehun, T. (2012). Helminthosis of sheep and goats in and around Haramaya, Eastern, Ethiopia. J. Vet. Med. and Anim. Health 4 (3): 48-55.

[14] Hansen, J. and Perry, B. (1994). The epidemiology, diagnosis and control of helminthes parasite of ruminants 2nded. Nairobi, Kenya. 
[15] Coles, G. C., Bauer, C., Borgsteede, F. H., Geerts, S., Klei, T. R., Taylor, M. A. and Waller, P. J. (1992). World Association for the Advancement of Veterinary Parasitology. Methods of the detection of anthelmintic resistance in nematodes of veterinary importance. Vet. Parasito144: 35-44.

[16] Thrusfield, M. V. (2005). Veterinary Epidemiology, 3rdedition. Oxford, England: Blackwell Science: 234-238.

[17] Soulsby, E. J. L. (1982). Helminthes arthropods andprotozoa of domesticated animal 7thed. London, Bailliere Tindall: 231250 .

[18] Tigist, K., Jemere, B. and Desie, Sh. (2015). Gastrointestinal nematodes of sheep and goats in three districts of Kaffaand Bench Maji Zone, South West, Ethiopia. Vet. J19 (2): 67-76.

[19] Mohammed, A., Haimanot, D., Tadele, K., Tilahun, Z. and Girma, K. (2015). Gastrointestinal nematodes of sheep in GursumWoreda of Eastern Hararghe Zone, Oromia Regional State, Ethiopia. Researcher 7(8): 45-54.

[20] Getachew, T., Urgessa, F. and Yacob, H. (2013). Field investigation of anthelmintic efficacy and risk factors for anthelmintics drug resistance in sheep at Bedelle District of Oromia Region, Ethiopia. Ethiop. Vet. J17(2): 37-49.

[21] Kumsa, B., Tigist, T., Teshale, R. and Bedru, H. (2011). Helminthes of sheep and goats in central Ethiopia during the Dry season. JAnimandVet. Advances10 (4): 1845-1849.

[22] Zajac, A. M. (2006). Gastrointestinal nematodes of small ruminants: Life cycle, anthelmintics, and diagnosis. Veterinary clinical Food Animal Practice22: 529-541.

[23] Diriba, L. and Birhanum, A. ( 2013). Prevalence of ovine gastrointestinal nematodes in and around Asella, SouthEastern, Ethiopia. J. Vet. Med. And Anim. Health 5(8): 222-228.
[24] Soulsby, E. J. (1986): Helminthes arthropods and protozoa of domesticated animals. 6th Ed. Bailliere, Tindall and Cassel, London.

[25] Bekele, J., Sheferaw, D., Getachew, D. and Denbarga, Y. (2013). Assessment of anthelmintic resistance in gastrointestinal nematodes of small ruminants, Dale district, Southern Ethiopia. J. Vet. Med. And Anim. Health 5: 257-261.

[26] Muluneh, J., Basaznew, B. and Mersh, Ch. (2014). Major Gastrointestinal Nematodes of small Ruminants in Dembia District, North West, Ethiopia. Europ. J Apply. Scie6 (2): 3036.

[27] Urquhart, G. M., Armour, J., Duncan, J. L., Dunn, A. M. and Jennings, F. W. (1996). Veterinary Parasitology, 2nd ed. Black well Science limited, London, UK.

[28] Niguse, A., Dawit, Sh. andTeka, F. (2014). Epidemiology and Chemotherapy of Gastrointestinal parasites of sheep in and around Jigjiga Eastern, Ethiopia. Europ. J. ofBio. Scien6 (2): 46-53.

[29] Achene, M., Basaznew, B., Mersha, Ch., Tewodros, T. andAyalew, B. (2013). Study on utilization and efficacy of commonly used anthelmintics against gastrointestinal nematodes in naturally infected sheep in North Gonder, NorthWest Ethiopia. Afr. Pharm and pharmacology7 (2): 679-684.

[30] Desie, Sh. and Amenu, A. (2010). Efficacy of selected anthelmintics against gastrointestinal nematodes of sheep owned by small holder farm in Wolaita, Southern Ethiopia. Ethiop. Vet. J. 14 (2): 31-38.

[31] Wassen, A. and Kumsa, B. (2008). Multiple anthelmintic resistances on a goat farm in Hawassa, Sourthern Ethiopia. Trop. Amin. Health. Prod 159: 593-598. 